\title{
Uncertainty-accounting environmental policy and management of water systems
}

\author{
Christian Baresel and Georgia Destouni
}

Number of pages: 3 (excluding this cover page)

Number of figures: 0

Number of tables: 0 


\section{Abatement measure costs and characteristics}

Abatement measure costs and characteristics are selected using available data from existing Swedish case studies (1). The costs of source abatement measures (soil- and water- covering) $C_{m}^{i j}\left(X_{m}^{i j}\right)$ are determined by the total surface area of waste deposits, because only entire covering of a deposit has significant abatement effect (1). Using an assumed lifetime of 50 years, annual costs are determined by using an annuity factor of 0.039 . Resulting costs are US $\$ 0.83 \mathrm{~m}^{2}$ (7.69 SEK=1 US\$, as of October 2003, which is maintained for comparative studies) for soil covering, US $\$ 0.06 \mathrm{~m}^{2}$ for water covering (2), and US\$ $0.26 \mathrm{~m}^{2}$ for constructed wetlands (1). For detailed discussions on constructed wetlands as mine water treatment measures and on cost impacts of wetland lifetime assumptions, see Aisling et al. (3) and Baresel et al. (1), respectively. Use of different wetland lifetimes than the ones used here affect specific results, but should not change the general conclusions of the present study. The assumed efficiency in reducing metal discharges is $98.8 \%$ and $99 \%$ for soil and water covers, respectively, (4). Various aspects related to the durability of these covering methods over the long time scales involved in mine water pollution abatement (5) are not considered in this study, but they may generally affect costeffective pollutant abatement solutions.

The zinc abatement effect of constructed wetlands is determined by chosen wetland area $A_{m}$ (considering also space constraints at the site), the zinc loading into the wetland $L_{k, m}=\alpha_{m} \sum_{i}\left(E_{i, m}^{\prime}-\sum_{j} X_{m}^{i j}\right)$, and an assumed wetland zinc load abatement capacity of $2 g$ (metal) $\mathrm{m}^{-2}$ $\mathrm{d}^{-1}(1)$ at un-abated upstream load conditions $L_{k, m}=\alpha_{m} \sum_{i} E_{i, m}^{\prime}$ (6). The resulting wetland zinc load abatement $\left(1-\sum_{i}\left(E_{i, m}^{\prime}-\sum_{j} \mathrm{X}_{m}^{i j}\right) / \sum_{i} E_{i, m}^{\prime}\right) \times 2 \mathrm{~g}($ zinc $) \mathrm{m}^{-2} \mathrm{~d}^{-1}$ is assumed to decrease linearly with upstream zinc emission abatement $\sum_{j} \mathrm{X}_{m}^{i j}$ and the cost $C_{m}\left(A_{m}\right)$ of the wetland abatement depends on constructed wetland area $A_{m}(6)$. 
It is not within the scope of this study to compare technological performances, advantages and drawbacks of different remediation and abatement measures; for such comparison and discussion, the reader is referred to, e.g. Elander et al. (4) and ERMITE Consortium (7).

\section{References}

(1) Baresel, C.; Larsén, K.; Destouni, G.; Gren, I.M. Economic Analysis of Mine Water Pollution Abatement on a Catchment Scale. ERMITE Report: D5, The European Commission fifth Framework Programme, Energy, Environment and Sustainable Development, Contract No EVK1-CT-2000-0078, University of Oviedo, 2003.

(2) Gustafsson, H.; Lundgren, T.; Lindvall, M.; Lindahl, L.Å.; Eriksson, N.; Jönsson, H.; Broman, P.G.; Göransson, T. The Swedish acid mine drainage experience: research, development and practice. Environmental impacts of mining activities, Emphasis on Mitigation and Remedial Measures. Springer, Heidelberg 1999, pp. 203-228.

(3) Aisling, D.O.; Olive, M.M.; Declan, A.M.; Otte, L.M. Wetlands for rehabilitation of metal mine wastes. Biology and Environment: Proceedings of the Royal Irish Academy 1999b (1), $11-17$.

(4) Elander, P.; Lindvall, M.; Håkansson, K. MiMi—prevention and control of pollution from mining waste products. State-of-the-art report, MiMi 1998: 2.

(5) Swedish Environmental Protection Agency (SEPA). Gruvavfall. Naturvårdsverket informerar. In Swedish. Broschyr. Swedish Environmental Protection Agency, Stockholm, 1986.

(6) Baresel, C.; Destouni, G.; Gren, I.M. The influence of metal source uncertainty on costeffective allocation of mine water pollution abatement in catchments. J. Environ. Manage. 2006, 78(2), 138-148. 
(7) ERMITE Consortium. Mining Impacts on the Freshwater Environment: Technical and Managerial Guidelines for Catchment-Focused Remediation. Younger, P. L.; Wolkersdorfer, C., Eds.; Mine Water Environ. 2004, 23, Suppl. Issue 1. 